\title{
Epigenetic Silencing of WNT Inhibitory Proteins; SFRP1 and DKK3 in Acute Leukemia
}

\author{
${ }^{(1)}$ Ahmed Ali Shams, ${ }^{(1)}$ Dalia GA, ${ }^{(2)}$ Shaimaa $S,{ }^{(3)}$ Omar Atef Tolba, \\ (1)Department of Clinical Pathology, Faculty of Medicine, Cairo University \\ ${ }^{(2)}$ Department of Clinical Pathology, Helwan Hospital. ${ }^{(3)}$ Cairo University Specialized \\ Pediatric Hospital, Pediatrics Department, Faculty of Medicine, Cairo University.
}

\begin{abstract}
Background: Over-activation of Wht (derived from names of two genes; Drosophila Wingless and mouse Int-1) pathway is incriminated in leukemogenesis. Functional loss of Wht antagonists; DKK (Dikkopf) and SFRPs (secreted frizzled-related protein), can contribute to Wnt hyper-activation. Silencing of Wnt antagonists by hypermethylation is reported in human malignancies as well as in hematopoietic malignancies. Our aim was to estimate the frequency and the possible impact of hypermethylation of the SFRP1 and DKK3 in acute leukemia. Methods: We evaluated SFRP1 and DKK3 methylation status using methylation specific polymerase chain reaction (MS-PCR) in 50 acute myeloid leukemia (AML) and 30 B-acute lymphoblastic leukemia (B-ALL) patients and 20 age and sex matched controls. Results: The frequency of methylation in B-ALL patients was 40\% for SFRP1, 40\% for DKK-3, in AML patients; the frequency was $44 \%$ for SFRP1, 36\% for DKK-3. All the control subjects had no aberrant methylation in either SFRP1 or DKK-3. B-ALL and $A M L$ groups showed no statistical significant difference in the frequency of SFRP1 or DKK-3 methylation. B-ALL patients with M-SFRP1 had a significantly higher mean platelets count and a lower mean age compared to B-ALL patients with UM-SFRP1, no other significant clinical or hematological difference was encountered between patients with M-SFRP1 and UM-SFRP1 or between M-DKK3 and UM-DKK3 patients in the ALL or the AML group. Different B-ALL and AML prognostic cytogenetic groups showed nearby frequency of SFRP1 and DKK3 methylation. Conclusion: SFRP1 and DKK3 methylation is frequent in acute leukemia. Treatment with demethylating agents may reverse the overactivated Wnt signaling in patients with methylated phenotype.
\end{abstract}

Key word: SFRP1; DKK3; methylation; AML; B-ALL; MS-PCR.

\section{INTRODUCTION}

Wnt proteins, derived from Drosophila Wingless $(\mathrm{Wg})$ and the mouse Int-1 genes, represent a large family of secreted cysteine-rich glycosylated proteins. This novel family of proteins is intimately involved in cellular signaling pathways that play a role in a variety of processes that involve embryonic cell patterning, proliferation, differentiation, orientation, adhesion, survival, and apoptosis ${ }^{1}$. Convincing evidence has established a crucial role for Wnt signaling in the maintenance and self-renewal of hematopoietic stem cells (HSC) ${ }^{2}$. 
Constitutive activation of the Wnt pathway has been found in solid tumors as well as hematopoietic malignancies ${ }^{3,4}$. Over-activation of Wnt signaling cascade have been demonstrated to have a role in leukemia pathogenesis; and dysregulation of the pathway seems to lead to a gain of self-renewal capacity of progenitor cells, resulting in the promotion of different forms of leukemia ${ }^{5-7}$.

WNT signaling is controlled by a number of natural Wnt antagonists that interfere with the ligand-receptor interaction, including members of the Dikkopf (DKK) family and the secreted frizzled-related protein (SFRP) family ${ }^{8}$.

The human Dkk-3 gene, located on chromosome $11 \mathrm{p} 15.1$ is a recently found mortalisation-related gene. It has been determined that Dkk-3 possesses an antiproliferative activity against tumor cells, suggesting that Dkk-3 may function as a tumor suppressor, and that its effect seems to be mediated by its ability to antagonize Wnt signaling, 9 . DKK-3 expression is largely attenuated in many immortalized and tumor derived cell lines ${ }^{11}$.

The family of SFRPs belongs to a group of proteins antagonizing the Wnt signaling pathway by interaction with the Wnt receptor. The functional role of SFRPs in normal and malignant hematopoiesis has not yet been systematically investigated. Four of the five known SFRP genes are characterized by a $\mathrm{CpG}$ island in the promoter region.

A loss of function of tumor suppressor genes can result from mutations, chromosomal deletions or epigenetic dysregulation ${ }^{12}$. The best studied epigenetic mechanism for silencing of cancer-related genes is hypermethylation of $\mathrm{CpG}$ islands in the promoter region of genes. $\mathrm{CpG}$ island hypermethylation of tumor suppressor genes has been described in almost all solid and hematopoietic malignancies ${ }^{13,14}$.

SFRP promoter hypermethylation is a frequent event in solid tumors, as was shown especially for SFRP1 and SFRP2 in colorectal cancer cells ${ }^{\mathbf{1 5}}$. Some studies proposed the epigenetic silencing of negative regulators of the Wnt signaling pathway may affect the Wnt regulatory proteins; DKK and SFRPs ${ }^{16,17}$.

Functional loss of Wnt antagonists can contribute to activation of the Wnt pathway and result in carcinogenesis through deregulation of cell proliferation and differentiation. Recent studies have shown that impaired activation of Wnt antagonists such as sFRP1 and DKK3 by promoter hypermethylation is present in several human malignancies $^{\mathbf{1 8 , 1 9}}$.

However, little is known about the potential role of promotor hypermethylation of Wnt antagonists (SFRP1, DKK3) in leukemia.

\section{Aim of the work:}

This study aimed to analyze the frequency and the possible impact of epigenetic hypermethylation of the SFRP1 and DKK3 genes in acute leukemia patients.

\section{SUBJECTS \& METHODS}

The present study was conducted on 80 newly diagnosed acute leukemia patients (30 with B-acute 
lymphoblastic leukemia and 50 patients with acute myeloid leukemia). Those patients were referred from Kasr Al Aini Faculty of Medicine Hospital, Cairo University, to be diagnosed in the Clinical Pathology Department during the period from May 2009 to June 2011. Twenty age and sex matched healthy volunteers were included as a control group. Informed consent was obtained from each participant or his/her guardians. The study was approved by the ethics committee of Cairo University.

The age of patients under study ranged from 9.0-68.0 years (mean $27.51 \pm 16.37), 23$ patients $(28.75 \%)$ were $\leq 16$ years (18 patients with BALL and 5 with AML), and 57 patients $(71.25 \%)$ were $\geq 17-68$ years (12 patients with B-ALL and 45 with AML). Sixty percent were males $(48 / 80)$ and $40 \%$ were females (32/80).

All cases were subjected to careful history-taking and comprehensive clinical examination. Diagnosis was established according to standard morphologic, cytochemical, immunophenotypic and cytogenetic criteria. The clinical characteristics known to be associated with prognosis were obtained: age, white blood cell count (WBC) at diagnosis, CD34 expression and cytogenetic analysis by conventional karyotype and/ or fluorescence in situ hybridization (FISH). The study was approved by the ethics committee of Cairo University. The clinical and laboratory data of the patients groups are summarized in tables 1 and 2 .

Aberrant promoter methylation of SFRP1 and Dkk-3 genes were determined by the method of methylation-specific PCR (MSP) as previously reported ${ }^{20}$. MSP distinguishes unmethylated alleles of a given gene based on DNA sequence alterations after bisulphite treatment of DNA, which converts unmethylated (but not methylated) cytosines to uracils. Subsequent PCR amplification using primers specific to sequences corresponding to either methylated or unmethylated DNA sequences was then performed. Primer sequences of Dkk-3 and SFRP1 are shown in table 3.

DNA extraction was done using QIAamp DNA Blood Mini Kits, (QIAGEN, Hilden, Germany) catalog number (51104). DNA Purification was performed fully automated on the QIAcube (QIAGEN, Hilden, Germany). Bisulfite DNA conversion was done using Qiagen EpiTect bisulfite kit, Hilden, Germany, catalog number (59401). Briefly, thermal cycler conditions, for bisulfite conversion, were as follows; 3 cycles of denaturation at $99^{\circ} \mathrm{C}$ for 5 minutes each. Each cycle was followed by incubation at $60^{\circ} \mathrm{C}$ for 25,85 and 175 minutes following the $1^{\text {st }}, 2^{\text {nd }}$ and 3 rd denaturation cycles respectively.

A volume of $2 \mu \mathrm{l}$ of the bisulfite treated DNAs were PCR amplified in a total volume of $50 \mu \mathrm{l}$. Initial activation step for 10 minutes at $95^{\circ} \mathrm{C}$ is required for 'Hot start' PCR, this was followed by 35 cycles consisting of denaturation at $95^{\circ} \mathrm{C}$ for $45 \mathrm{~s}$, annealing for $30 \mathrm{~s}$ at $60^{\circ} \mathrm{C}$ and extension at $72^{\circ} \mathrm{C}$ for $30 \mathrm{~s}$. This was followed by a final 10 -min extension at $72^{\circ} \mathrm{C}$ for all primers sets. DNA from healthy donors was used as negative controls for methylation- 
specific assays. PCR products were separated on $2 \%$ agarose gel, stained by ethidium bromide and visualized on an ultraviolet trans-illuminator.

\section{Statistical analysis:}

Data was analyzed using SPSS win statistical package version 17 (SPSS Inc., Chicago, IL). Numerical data were expressed as mean and standard deviation or median and range as appropriate. Qualitative data were expressed as frequency and percentage. Chi-square test (Fisher's exact test) was used to examine the relation between qualitative variables. For quantitative data, comparison between two groups was done using Mann-Whitney test (non-parametric ttest). Comparison between 3 groups was done using Kruskal-Wallis test (non-parametric ANOVA) followed post-Hoc "Schefe test" on rank of variables for pair-wise comparison. A p-value $<0.05$ was considered significant.

\section{RESULTS}

The frequency of methylation in B-acute lymphoblastic leukemia (BALL) patients at diagnosis was $40 \%$ (12/30) for SFRP1, 40\% (12/30) for DKK-3 and $13 \%$ (4/30) for methylation of both SFRP1 and DKK3. Hypermethylation of at least one gene occurred in $66.7 \%(20 / 30)$ of the B-ALL patients, while for acute myeloid leukemia (AML) patients, the frequency of methylation was $44 \%$ $(22 / 50)$ for SFRP1, 36\% (18/50) for DKK-3, 24\% (12/50) for methylation of both SFRP1 and DKK3 and the frequency of methylation of at least one of these two genes was $56 \%$ $(28 / 50)$. All the control subjects
(100\%) had no aberrant methylation in SFRP1 or DKK-3 genes. A significantly higher frequency of methylation was found in acute leukemia patients compared to control subjects, $\mathrm{p}$ value (0.001). While no significant difference was found by comparing B-ALL and AML groups as regards the frequency of SFRP1 or DKK-3 methylation, $p$ value $(>0.05)$.

The frequency of methylation in different B-ALL FAB categories was $75 \%(6 / 8), 62.5 \%(10 / 16), 50 \%$ (2/4) and $100 \%(2 / 2)$ for pro $\mathrm{B}$, common $\mathrm{B}$, pre $B$ and mature $B$ subtypes respectively, on the other-hand the AML group FAB categories showed a frequency of methylation of $25 \%$ (2/8), 55\% (12/22), 100\% (8/8), 75\% (6/8), 0\% (0/4) for M1, M2, M3, M4 and M5 respectively, as M0, M6 and M7 weren't encountered among patients group of the current study.

B-ALL patients were grouped according to their cytogenetic and molecular findings into; good [hyperdiploidy >50], intermediate [normoploidy and hyperdiploidy 4750], bad [hypodiploidy, BCR-ABL $\mathrm{t}(9 ; 22)$ and unclassified (no available data) prognostic groups, the frequency of SFRP1 methylation among these groups was $50 \%(2 / 4), 28.5 \%$ (4/14), $60 \%(6 / 10)$ and $0 \%(0 / 2)$ respectively, while DKK-3 aberrant methylation frequency was $100 \% \quad(4 / 4), 14 \%$ $(2 / 14), 40 \%(4 / 10)$ and $100 \%$ (2/2) for the same ordered groups.

Cytogenetic and molecular grouping of AML patients into; Good [t $(8 ; 21)$ and $\mathrm{t}(15 ; 17)]$, bad (trisomy 8 ) and unclassified prognostic groups, revealed a frequency of SFRP1 methylation of $75 \%(12 / 16), 0 \%(0 / 6)$, and $35.5 \%(10 / 28)$ respectively, while 
the frequency of DKK-3 aberrant methylation was $37.5 \%$ (6/16), $66.7 \%$ $(4 / 6)$, and $28.5 \%(8 / 28)$ for the same ordered groups.

B-ALL patients with M-SFRP1 had a significantly higher mean platelets count and a lower mean age compared to B-ALL patients with UM-SFRP1, $\mathrm{P}$ value $(<0.05)$, otherwise no significant difference, between M-SFRP1 and UM-SFRP1 ALL patients or between M-SFRP1 and UM-SFRP1 AML patients as regards any other clinical or hematological data, was encountered, $\mathrm{P}$ value $(>0.05)$.
As for B-ALL and AML patients with aberrant M-DKK3, they showed no significant difference as regards the clinical or hematological data when they were compared to UMDKK3 B-ALL and AML patients respectively, $\mathrm{P}$ value $(>0.05)$.

AML patients with M-SFRP1 and UM-SFRP1 had a frequency of CD34 positivity of $9 \%(2 / 22)$ and $22 \%$ (6/28) respectively, while those with M-DKK3 and UM-DKK3 had a frequency of CD34 positivity of $11 \%$ $(2 / 18)$ and $19 \%(6 / 32)$ respectively.

Table 1: Clinical characteristics of B-ALL and AML patients according to SFRP1 gene methylation status.

\begin{tabular}{|c|c|c|c|c|c|c|c|c|}
\hline & \multicolumn{2}{|c|}{ B-ALL $(\mathbf{N}=30)$} & \multirow{2}{*}{$\begin{array}{l}\mathbf{P} \\
\text { value }\end{array}$} & \multicolumn{3}{|c|}{$\operatorname{AML}(\mathrm{N}=50)$} & \multirow{2}{*}{$\begin{array}{l}\mathbf{P} \\
\text { Value }\end{array}$} \\
\hline & & M-SFRP1 & $\begin{array}{l}\text { UM- } \\
\text { SFRP1 }\end{array}$ & & \multicolumn{2}{|c|}{ M-SFRP1 } & $\begin{array}{l}\text { UM- } \\
\text { SFRP1 }\end{array}$ & \\
\hline \multicolumn{2}{|c|}{ Number, \% } & $12(40)$ & $18(60)$ & NS & \multicolumn{2}{|l|}{$22(44)$} & $28(56)$ & NS \\
\hline \multicolumn{2}{|c|}{ Sex (male) N, \% } & $10(41.7 \%)$ & $14(58.3 \%)$ & \multirow[t]{2}{*}{----- } & \multicolumn{2}{|l|}{$10(41.7 \%)$} & $14(58.3 \%)$ & \multirow[t]{2}{*}{ NS } \\
\hline \multicolumn{2}{|c|}{ Sex (female) N, \% } & $2(33.3 \%)$ & $4(66.7 \%)$ & & \multicolumn{2}{|l|}{$12(46.2 \%)$} & $14(53.8 \%)$ & \\
\hline \multicolumn{5}{|c|}{ FAB subtypes } & \multicolumn{4}{|c|}{ FAB subtypes } \\
\hline \multicolumn{2}{|c|}{ Pro B-ALL, L2, N=8 } & $4(50 \%)$ & $4(50 \%)$ & ------- & M1, $\mathbf{N}=8$ & 0 & $8(100 \%)$ & ------- \\
\hline \multicolumn{2}{|c|}{$\begin{array}{l}\text { Common B-ALL (L1), } \\
\mathrm{N}=4\end{array}$} & $2(50 \%)$ & $2(50 \%)$ & & M2, $\mathbf{N}=22$ & $8(36 \%)$ & $14(64 \%)$ & \\
\hline \multicolumn{2}{|c|}{$\begin{array}{l}\text { Common B-ALL (L2), } \\
\mathrm{N}=12\end{array}$} & $4(33.3 \%)$ & $8(66.7 \%)$ & & M3, $\mathbf{N}=8$ & $8(100 \%)$ & 0 & \\
\hline \multicolumn{2}{|c|}{ Pre B-ALL, L1, N=4 } & $2(50 \%)$ & $2(50 \%)$ & $\begin{array}{ll}------- \\
\end{array}$ & M4, $\mathbf{N}=8$ & $6(75 \%)$ & $2(25 \%)$ & ------- \\
\hline \multicolumn{2}{|c|}{ Mature B-ALL, L3, N=2 } & 0 & $2(100 \%)$ & $\begin{array}{ll}------ \\
\end{array}$ & M5, $\mathbf{N}=4$ & 0 & $4(100 \%)$ & $\begin{array}{ll}------ \\
\end{array}$ \\
\hline \multicolumn{2}{|c|}{ Age, years } & $20.6 \pm 11.9$ & $32.3 \pm 17.8$ & 0.034 & \multicolumn{2}{|l|}{$26.2 \pm 13.9$} & $29.2 \pm 18.5$ & NS \\
\hline \multicolumn{2}{|c|}{ WBCs, $\times 10^{9} / \mathrm{L}$} & $11.9 \pm 7.8$ & $11.7 \pm 9.7$ & NS & \multicolumn{2}{|l|}{$19 \pm 15.6$} & $31.3 \pm 27.9$ & NS \\
\hline & $7.8 \pm 1.7$ & $6.1 \pm 2.2$ & NS & \multicolumn{2}{|l|}{$6.6 \pm 1.5$} & $5.9 \pm 1.7$ & NS \\
\hline \multicolumn{2}{|c|}{ PIts, $\times 10^{9} / \mathrm{L}$} & $89.3 \pm 59.2$ & $37.7 \pm 13.7$ & 0.036 & \multicolumn{2}{|l|}{$46.3 \pm 15.9$} & $49.3 \pm 21.2$ & NS \\
\hline \multicolumn{2}{|c|}{ Blasts, \% } & $52.2 \pm 25.4$ & $77.1 \pm 20.4$ & NS & \multicolumn{2}{|l|}{$67.2 \pm 18.9$} & $73.5 \pm 12.1$ & NS \\
\hline \multirow{4}{*}{ 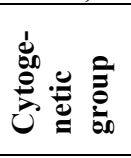 } & Good & $2(16.7 \%)$ & $2(11.1 \%)$ & ------- & \multicolumn{2}{|l|}{$12(54.5 \%)$} & $4(14.3 \%)$ & ------- \\
\hline & Bad & $6(50 \%)$ & $4(22.2 \%)$ & $\begin{array}{ll}------ \\
--1\end{array}$ & \multicolumn{2}{|l|}{$0(0 \%)$} & $6(21.4 \%)$ & ------- \\
\hline & Intermediate & $4(33.3 \%)$ & $10(55.6 \%)$ & ------- & \multicolumn{2}{|l|}{------- } & ------- & ------- \\
\hline & Other & $0(0 \%)$ & $2(11.1 \%)$ & -------- & $10(45.5 \%)$ & & $18(64.3 \%)$ & ------- \\
\hline
\end{tabular}

NS: not significant $\mathrm{P}$ value $(>0.05)$. N: number. Hb: hemoglobin. Plats: platelets. 
Table 2: Clinical characteristics of ALL and AML patients according to DKK3 gene methylation status.

\begin{tabular}{|c|c|c|c|c|c|c|c|c|}
\hline & \multicolumn{2}{|c|}{ B-ALL (N=30) } & \multirow{2}{*}{$\begin{array}{l}P \\
\text { value }\end{array}$} & \multicolumn{3}{|c|}{ AML (N=50) } & \multirow{2}{*}{$\begin{array}{l}\mathbf{P} \\
\text { value }\end{array}$} \\
\hline & & M-DKK3 & $\begin{array}{l}\text { UM- } \\
\text { DKK3 }\end{array}$ & & \multicolumn{2}{|l|}{ M-DKK3 } & UM-DKK3 & \\
\hline \multicolumn{2}{|c|}{ Number, \% } & $12(40)$ & $18(60)$ & NS & \multicolumn{2}{|l|}{$18(34)$} & $32(64)$ & NS \\
\hline \multicolumn{2}{|c|}{ Sex(male) } & $8(33.3 \%)$ & $16(66.7 \%)$ & \multirow[t]{2}{*}{----- } & \multicolumn{2}{|l|}{$8(33.3 \%)$} & $16(66.7 \%)$ & \multirow[t]{2}{*}{ NS } \\
\hline \multicolumn{2}{|c|}{ Sex(female) } & $4(66.7 \%)$ & $2(33.3 \%)$ & & \multicolumn{2}{|l|}{$10(38.5 \%)$} & $16(61.5 \%)$ & \\
\hline \multicolumn{5}{|c|}{ FAB subtypes } & \multicolumn{4}{|c|}{ FAB subtypes } \\
\hline \multicolumn{2}{|c|}{ Pro B-ALL, L2, N=8 } & $2(25 \%)$ & $6(75 \%)$ & ------- & M1, $\mathbf{N}=8$ & $2(25 \%)$ & $6(75 \%)$ & ------- \\
\hline \multicolumn{2}{|c|}{$\begin{array}{l}\text { Common B-ALL (L1), } \\
\mathrm{N}=4\end{array}$} & 0 & $4(100 \%)$ & & $\mathbf{M} 2, \mathbf{N}=22$ & $10(45 \%)$ & $12(55 \%)$ & \\
\hline \multicolumn{2}{|c|}{$\begin{array}{l}\text { Common B-ALL (L2), } \\
\mathrm{N}=12\end{array}$} & $6(50 \%)$ & $6(50 \%)$ & & $\mathbf{M 3}, \mathbf{N}=8$ & $2(25 \%)$ & $6(75 \%)$ & \\
\hline \multicolumn{2}{|c|}{ Pre B-ALL, L2, N=4 } & $2(50 \%)$ & $2(50 \%)$ & ------- & $\mathrm{M} 4, \mathrm{~N}=8$ & $4(50 \%)$ & $4(50 \%)$ & ------- \\
\hline \multicolumn{2}{|c|}{$\begin{array}{l}\text { Mature B-ALL, L3, } \\
\mathbf{N = 2}\end{array}$} & $2(100 \%)$ & 0 & & M5, $\mathbf{N}=4$ & 0 & $4(100 \%)$ & \\
\hline \multicolumn{2}{|c|}{ Age, years } & $20.2 \pm 15.4$ & $29.6 \pm 16.0$ & NS & \multicolumn{2}{|c|}{$23.9 \pm 14.5$} & $31.6 \pm 17.9$ & NS \\
\hline \multicolumn{2}{|c|}{ WBCs, $x 10 \% / L$} & $8.3 \pm 4$ & $14.1 \pm 10.4$ & NS & \multicolumn{2}{|c|}{$24.7 \pm 12.6$} & $26.6 \pm 28.5$ & NS \\
\hline \multicolumn{2}{|c|}{$\mathrm{Hb}, \mathrm{g} / \mathrm{dl}$} & $7.7 \pm 2.6$ & $6.2 \pm 1.7$ & NS & \multicolumn{2}{|l|}{$7.1 \pm 1.5$} & $5.7 \pm 1.5$ & NS \\
\hline \multicolumn{2}{|c|}{ Plts, $x 10^{9} / \mathrm{L}$} & $63.3 \pm 54.7$ & $56 \pm 40.5$ & NS & \multicolumn{2}{|l|}{$48.7 \pm 20.2$} & $47.6 \pm 18.5$ & NS \\
\hline \multicolumn{2}{|c|}{ Blasts, \% } & $59.7 \pm 21.7$ & $72.1 \pm 27.1$ & NS & \multicolumn{2}{|l|}{$71.4 \pm 19.4$} & $70.3 \pm 13.3$ & NS \\
\hline \multirow{4}{*}{ 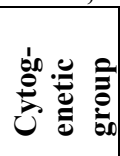 } & Good & $4(33.3 \%)$ & $0(0 \%)$ & ------- & \multicolumn{2}{|l|}{$6(33.3 \%)$} & $10(31.25 \%)$ & ------- \\
\hline & Bad & $4(33.3 \%)$ & $6(33.3 \%)$ & ------- & \multicolumn{2}{|l|}{$4(22.25 \%)$} & $2(6.25 \%)$ & ------- \\
\hline & Intermediate & $2(16.7 \%)$ & $12(66.7 \%)$ & ------- & \multicolumn{2}{|l|}{------- } & ------- & ------- \\
\hline & Other & $2(16.7 \%)$ & $0(0 \%)$ & ------- & $8(44.45 \%)$ & & $20(62.5 \%)$ & ------- \\
\hline
\end{tabular}

NS: not significant P value $(>0.05)$. N: number. Hb: hemoglobin. Plats: platelets.

Table 3: The sequence of the primers used in the present work.

\begin{tabular}{|c|c|}
\hline & Primer sequence \\
\hline \multirow[t]{2}{*}{ M-SFRP1 } & F: 5-TGTAGTTTTCGGAGTTAGTGTCGCGC-3 \\
\hline & R: 5-CCTACGATCGAAAACGACGCGAACG-3 \\
\hline \multirow[t]{3}{*}{ UM-SFRP1 } & F: 5-GTTTTGTAGTTTTTGGAGTTAGTGTTGTGT-3 \\
\hline & R: 5-CTCAACCTACAATCAAAAACAACACAAACA-3 \\
\hline & $\left(\right.$ Veeck et al.. $\left.{ }^{33}\right)$ \\
\hline \multirow[t]{2}{*}{ M-DKK-3 } & F: 5-CGGTTTTTTTTCGTTTTCGGGC-3 \\
\hline & R: 5-CGCCTATATATCCCGAAACGCG-3 \\
\hline \multirow[t]{3}{*}{ UM-DKK-3 } & F: 5-GGGGTTTTGGTTTTTTTTTGTTTTTGGGT-3 \\
\hline & R: 5-AACCACCACCTATATATCCCAAAACACA-3 \\
\hline & (Roman-Gomez et al., $\left.{ }^{25}\right)$ \\
\hline
\end{tabular}




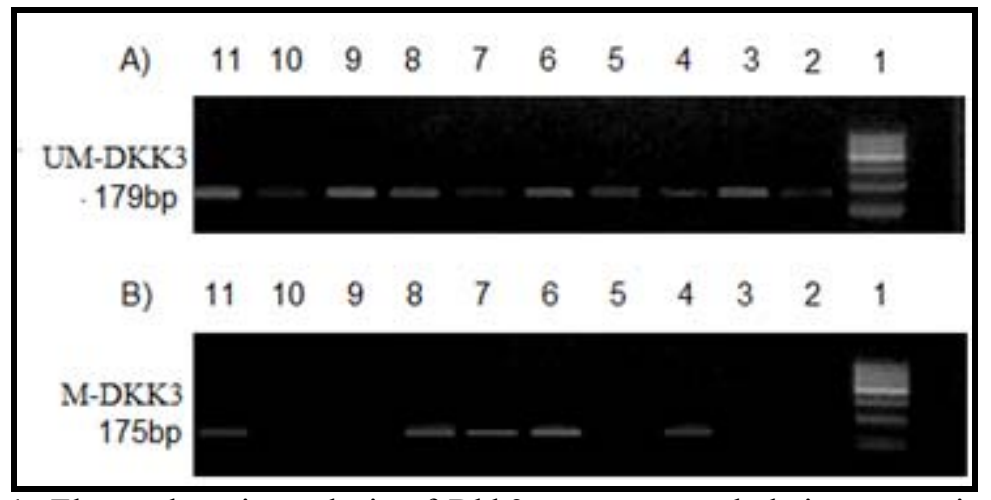

Figure 1: Electrophoretic analysis of Dkk3 promoter methylation status in control subjects and acute leukemia patients. Lane 1; molecular weight ladder 100-1000 bp. Lanes $2 \& 3$ represent control subjects, lanes $2 \mathrm{a} \& 3 \mathrm{a}$ denoting presence of UM-DKK3, lanes $2 b, 3 b$ denoting absence of M-DKK3. Lanes 5,9,10 represent acute leukemia patients with unmethylated phenotype, lanes $5 \mathrm{a}, 9 \mathrm{a}, 10 \mathrm{a}$ denoting presence of UMDKK3, lanes 5b,9b,10b denoting absence of M-DKK3. Lanes 4,6,7,8,11 represent acute leukemia patients with methylated phenotype, lanes $4 \mathrm{a}, 6 \mathrm{a}, 7 \mathrm{a}, 8 \mathrm{a}, 11 \mathrm{a}$ denoting presence of UM-DKK3, lanes $4 b, 6 b, 7 b, 8 b, 11 b$ denoting presence of M-DKK3.

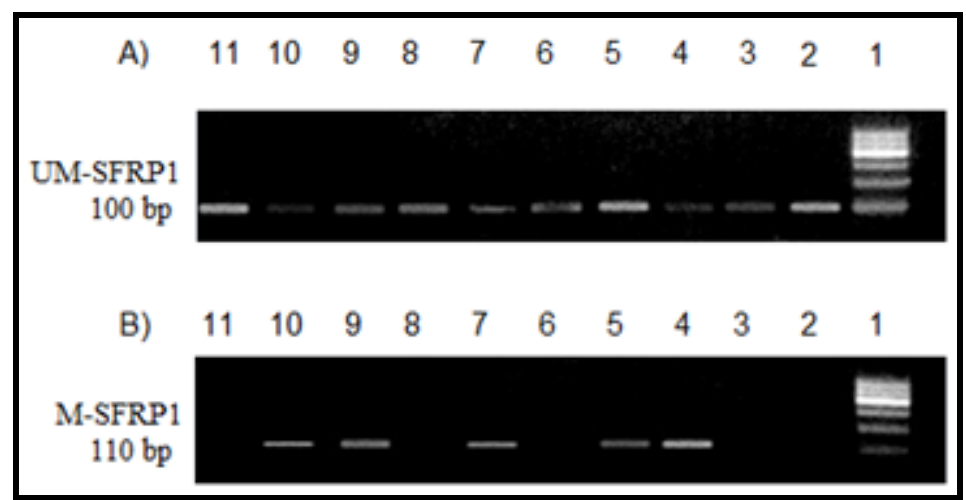

Figure 2: Electrophoretic analysis of SFRP1 promoter methylation status in control subjects and acute leukemia patients. Lane 1; molecular weight ladder 100-1000 bp. Lanes $2 \& 3$ represent control subjects, lanes $2 \mathrm{a} \& 3$ a denoting presence of UM-SFRP1, lanes $2 b, 3 b$ denoting absence of M-SFRP1. Lanes 6,8,11 represent acute leukemia patients with unmethylated phenotype, lanes $6 \mathrm{a}, 8 \mathrm{a}, 11 \mathrm{a}$ denoting presence of UMSFRP1, lanes $6 b, 8 b, 11 b$ denoting absence of M- SFRP1. Lanes 4,5,7,9,10 represent acute leukemia patients with methylated phenotype, lanes 4a,5a,7a,9a,10a denoting presence of UM- SFRP1, lanes $4 b, 5 b, 7 b, 9 b, 10 b$ denoting presence of M- SFRP1. 


\section{DISCUSSION}

The "cancer stem cell" model postulates that tumors initiate from a sub-population of cancer cells that are pluripotent, and that most cells in the tumor are differentiated progeny of the cancer stem cells. Activation of the Wnt signaling pathway is associated with expansion of several stem cell compartments and is often deregulated in human malignancies ${ }^{21}$.

Aberrant activation of the Wnt pathway has been demonstrated to contribute to leukemogenesis but, in contrast to solid tumors, no activating mutations in the genes of the Wnt pathway, have been described in myeloid or lymphatic malignancies until now ${ }^{22}$, suggesting that abnormal regulation of this pathway is mediated by other mechanisms ${ }^{17}$.

Epigenetic gene silencing is increasingly being recognized as a common way in which cancer cells inactivate cancer related genes. In addition to its pathogenic implications, promoter hypermethylation and transcriptional repression of functionally important cancer-related genes may also affect tumor behavior, impacting clinical outcomes. Epigenetic silencing of negative regulators of Wnt signaling has been found in AML for Wnt inhibitory factor 1 (WIF1) preferentially in acute promyelocytic leukemia (APL) and for DKK1 in Core Binding Factor (CBF) leukemia. In addition, SFRP gene silencing in association with promoter hypermethylation has been described in other hematopoietic malignancies such as ALL and multiple myeloma $(\mathrm{MM})^{23,24}$.

Because each tumor may harbor multiple genes susceptible to promoter hypermethylation, individual tumors exhibit different frequencies of hypermethylation profile potentially predictive of a patient's clinical outcome $^{25}$.

Despite the growing knowledge about the definite role of activated Wnt pathway in malignant hematopoiesis, the role of Wnt inhibitory proteins in leukemogenesis is still not well-defined.

The present study has addressed the question of the role and the frequency of epigenetic silencing of the Wnt antagonists SFRP1 and DKK3 in AML and B-ALL.

The frequency of aberrant methylation of SFRP1 among B-ALL patients' samples was $40 \%$ in the present study. In agreement with our study, nearly the same frequency (38 and $39.3 \%$ ) of SFRP1 methylation in ALL were reported by two other studies ${ }^{17,26}$.

The current study reported a frequency of $40 \%$ for DKK3 aberrant methylation among B-ALL patients. Roman-Gomez, et al. ${ }^{25}$ reported that Dkk-3 methylation was detected at diagnosis in $33 \%$ (60 out of 183 ) of patients with ALL. Reviewing their study, the frequency of DKK-3 was calculated among $\mathrm{B}$ and T-ALL patients altogether while the frequency of M-DKK-3 among BALL was found to be $42 \%(64 / 152)$ in concordance to the present results.

Our reported SFRP1 methylation frequency, was 44\% among AML patients, frequencies ranging between 
29 and $34 \%$ were reported by other studies ${ }^{22,26,27,28}$.

The frequency of DKK3 aberrant methylation among AML patients was $36 \%$ in the present study. In contrast, a much lower $(8 \%)$ and a much higher frequencies for DKK3 methylation among AML patients were reported by 2 other studies ${ }^{\mathbf{2 8 , 2 9}}$ respectively.

Reviewing the study done by Griffiths et al. ${ }^{28}$ who reported the $8 \%$ frequency for DKK3 methylation; we observed that relapsed AML and AML with antecedent MDS patients represented the main core of their study, on the contrary to the present study which was conducted on newly diagnosed patients. This may explain these discrepant results as treatment with chemotherapeutic agents, as the case in relapsed AML and AML with antecedent MDS, was reported to decrease methylation events ${ }^{\mathbf{3 0}}$.

The frequency of SFRP1 and/or DKK3 methylation varied among different AML and ALL, FAB subtypes with a special concern to M3, where $100 \%(8 / 8)$ of patients showed methylation of SFRP1 gene. M5 subtype included 4 patients, none of them showed methylation of any of SFRP1 or DKK3 genes.

No meaningful difference was encountered, when different B-ALL or AML prognostic cytogenetic groups were compared as regards the frequency of SFRP1 or DKK3 methylation, however the small sample size within these groups couldn't enable the statistical analysis.

In agreement with our study findings, Griffiths et al. ${ }^{28}$ and RomanGomez et al. ${ }^{17}$ reported no significant differences in the frequency of SFRP1 or DKK3 methylation between the normal karyotype group and other groups with abnormal karyotypes in AML and ALL patients respectively.

With the exception of higher mean platelets count, and lower mean age in B-ALL patients with M-SFRP1 compared to those with UM-SFRP1, no other significant difference was encountered, between M-SFRP1 and UM-SFRP1 B-ALL patients or between M-SFRP1 and UM-SFRP1 AML patients as regards any other clinical or hematological data.

In consistence to the present study findings, recent studies reported the same in $\mathrm{ALL}^{17}$ and AML ${ }^{22,28}$.

In contrast, Hou et al., ${ }^{27}$ reported that AML patients with aberrant methylation of at least one Wnt inhibitor had lower WBC count and tended to be older than others. However, reviewing their study, they evaluated the methylation status of seven Wnt inhibitors genes (including SFRP1) and the previous findings were matched for AML patients with methylation of any of these genes.

We couldn't signal any significant difference in the clinical or hematological data of ALL or AML patients with aberrant M-DKK3 compared to those with UM-DKK3.

The current results are in agreement with those of RomanGomez et al. ${ }^{17,25}$ who found no significant difference between ALL patients with methylated DKK3 and those with unmethylated DKK3, as regards different clinical and hematological data.

AML patients with M-SFRP1 and UM-SFRP1 had a frequency of CD34 positivity of $9 \%(2 / 22)$ and $21 \%$ (6/28) respectively, while those with M-DKK3 and UM-DKK3 had a 
frequency of CD34 positivity of $11 \%$ $(2 / 18)$ and $19 \%(6 / 32)$ respectively.

In a trial to prove the impact of aberrant methylation of DKK3 and SFRP1 on their expression levels; Roman-Gomez et al. $^{25}$ quantitated the expression level of DKK3 besides the analysis of the DKK3 promoter methylation status in 183 ALL patients and reported that 60 ALL patients $(33 \%)$ were methylated for DKK3 and all of them (100\%) showed decreased Dkk3 expression; indicating that methylation within Dkk3 promoter strongly correlated with decreased constitutive expression of Dkk-3 in ALL patients. The same was confirmed for SFRP1 by another study $^{17}$.

Despite the findings reported by other studies as well as ours, that aberrant DKK3 or SFRP1 methylation wasn't linked with many of the clinical, hematological and cytogenetic variants that are correlated with prognosis of ALL and AML patients. However, studies that could retrospectively analyzed the patients data, could conclude a significant correlation between DKK3 and/or SFRP1 methylation with shorter disease free survival as well as overall survival in patients with ALL ${ }^{17,25}$, and $\mathrm{AML}^{27}$ implicating DKK3 and SFRP1 methylation with poor prognosis.

There is growing evidence that the stem cell populations in various leukemias are resistant to standard therapies. Thus new therapies targeted against stem cells need to be identified. Signal transduction pathways that regulate normal stem cell activity; like the Wnt pathway, could provide excellent therapeutic targets $^{\mathbf{2 1}}$. Therefore, in vitro treatment with demethylating agents, like 5-aza2-deoxycytidine and decitabine that reverse the silencing effect of promoter methylation on Wnt inhibitory molecules like DKK3, SFRP1, may lead to down regulation of activated Wnt signaling pathway in patients with acute leukemia. This hypothesis was validated in ALL and $\mathrm{AML}^{17,31}$ respectively.

As DNA methylation changes could be used as a marker for minimal residual disease in $\mathrm{AML}^{32}$, monitoring of hypermethylation of SFRP1 and DKK3 genes may also serve for relapse prediction in ALL and AML after being validated by studies dealing with large cohort of acute leukemia patients in the follow up period.

In conclusion; our piece of work highlighted that SFRP1 and DKK3 silencing, by promoter methylation, is an early and a common event in the evolution of acute leukemia, methylation of SFRP1 and DKK3 may serve as potential independent biomarkers for early detection of acute leukemia. Patients with aberrant methylation phenotype may benefit from treatment with demethylating agents as that line of management expected to damp down the Wnt signaling activity and hence the activity of the disease. Our study also offers a preliminary basis for further studies to monitor hypermethylation of Wnt antagonists as a marker for minimal residual disease.

\section{REFERENCES}

1. Nelson WJ and Nusse R. (2004): Convergence of Wnt, beta-catenin, and cadherin 
pathways. Science 303:14831487.

2. Nemeth MJ and Bodine DM. (2007): Regulation of hematopoiesis and the hematopoietic stem cell niche by Wnt signaling pathways, Cell Res., 17:746-758.

3. Clevers, H. (2004): Wnt breakers in colon cancer. Cancer Cell, 5:5-6.

4. Sansom OJ, Reed KR, Hayes AJ, Ireland H, Brinkmann $\mathrm{H}$, Newton IP, Batlle E, SimonAssmann P, Clevers H, Nathke IS, Clarke AR, Winton DJ. (2004): Loss of Apc in vivo immediately perturbs Wnt signaling, differentiation, and migration. Genes Dev., 15:13851390.

5. Khan NI and Bendall LJ. (2006): Role of WNT signaling in normal and malignant hematopoiesis. Histol. Histopathol., 21:761-774.

6. Deshpande AJ and Buske C. (2007): Knocking the Wnt out of the sails of leukemia stem cell development, Cell Stem Cell 1:597-598.

7. Zhao C, Blum J, Chen A, Kwon HY, Jung SH, Cook JM, Lagoo A, Reya T. (2007): Loss of $\beta$ catenin impairs the renewal of normal and CML stem cells in vivo. Cancer Cell 12:528-541.

8. Reya T, Duncan AW, Ailles L, Ailles L, Domen J, Scherer DC, Willert K, Hintz L, Nusse R, Weissman IL. (2003): A role for Wnt signaling in self-renewal of hematopoietic stem cells. Nature 423:409-414.
9. Taipale $J$ and Beachy PA. (2001): The Hedgehog and Wnt signaling pathways in cancer. Nature 411: 349-354.

10. Tsuji T, Nozaki I, Miyazaki M, Sakaguchi M, Pu H, Hamazaki Y, Iijima O, Namba M. (2001): Anti-proliferative activity of REIC/Dkk-3 and its significant down-regulation in non-small-cell lung carcinomas. Biochem. Biophys. Res. Commun., 289: 257-263.

11. Tsuji T, Miyazaki M, Sakaguchi M, Sakaguchi M, Inoue Y, Namba M. (2000): A REIC gene shows downregulation in human immortalized cells and human tumor-derived cell lines. Biochem. Biophys. Res. Commun., 268:20-24.

12. Jost E, Osieka $R$ and Galm $O$ (2006): Targeting the epigenome in hematopoietic malignancies. Letters in Drug Design \& Discovery 3:242-252.

13. Herman JG and Baylin SB. (2003): Gene silencing in cancer in association with promoter hypermethylation. New England Journal of Medicine 349:20422054.

14. Galm O, Herman JG and Baylin SB. (2006): The fundamental role of epigenetics in hematopoietic malignancies. Blood Reviews 20:1-13.

15. Suzuki H, Watkins DN, Jair KW, Schuebel KE, Markowitz SD, Chen WD, Pretlow TP, Yang B, Akiyama Y, Van Engeland M, Toyota M, Tokino T, Hinoda Y, Imai K, Herman JG, Baylin SB. (2004): Epigenetic inactivation of SFRP 
genes allows constitutive WNT signaling in colorectal cancer. Nature Genetics 36:417-422.

16. Chim CS, Chan WW, Pang A and Kwong YL. (2006): Preferential methylation of Wnt inhibitory factor-1 in acute promyelocytic leukemia: an independent poor prognostic factor. Leukemia 20: 907-909.

17. Roman-Gomez J, Cordeu L, Agirre $\mathrm{X}$, Jiménez-Velasco A, San José-Eneriz E, Garate L, Calasanz MJ, Heiniger A, Torres A, Prosper F. (2007): Epigenetic regulation of Wntsignaling pathway in acute lymphoblastic leukemia. Blood 109: 3462-3469.

18. Mazieres J, He B, You L, Xu Z, Lee AY, Mikami I, Reguart N, Rosell R, McCormick F, Jablons DM. (2004): Wnt inhibitory factor- 1 is silenced by promoter hyper-methylation in human lung cancer. Cancer Res., 64:4717-4720.

19. Batra S, Shi Y, Kuchenbecker KM, He B, Reguart N, Mikami I, You $\mathrm{L}$, $\mathrm{Xu} \mathrm{Z}$, Lin $\mathrm{YC}$, Clément G, Jablons DM. (2006): Wnt inhibitory factor-1, a Wnt antagonist, is silenced by promoter hypermethylation in malignant pleural mesothelioma. Biochem. Biophys. Res. Commun., 342:1228-1232.

20. Herman JG, Graff JR, Myohanen S, Nelkin BD, Baylin SB. (1996): Methylation-specific PCR: A novel PCR assay for methylation status of $\mathrm{CpG}$ islands. Proc. Natl. Acad. Sci. USA., 93:9821-9826.
21. Valkenburg KC, Graveel CR, Zylstra-Diegel CR, Zhong $\mathrm{Z}$ and Williams BO (2011): $\mathrm{Wnt} / \beta$-catenin signaling in normal and cancer stem cells. Cancers 3:2050-2079.

22. Jost E, Schmid J, Wilop S, Schubert C, Suzuki H, Herman JG, Osieka R, Galm O. (2008): Epigenetic inactivation of secreted Frizzled-related proteins in acute myeloid leukemia. British Journal of Hematology 142:745-753.

23. Roman-Gomez J, Jimenez A, Castillejo JA, Barrios M, Heiniger A, Torres A. (2003): The role of DNA hypermethylation in the pathogenesis and prognosis of acute lymphoblastic leukemia. Leuk. Lymphoma 44:1855-1864.

24. Bovolenta P, Esteve $P$, Ruiz JM, Cisneros E, Lopez-Rios J. (2008): Beyond Wnt inhibition: new functions of secreted frizzled-related proteins in development and disease. Journal of Cell Science 121(Pt 6) :737746.

25. Roman-Gomez J, JimenezVelasco A, Castillejo JA, Agirre $\mathbf{X}$, Barrios $M$, Navarro $G$, Molina FJ, Calasanz MJ, Prosper F, Heiniger A, Torres A. (2004): Promoter hypermethylation of cancerrelated genes: A strong independent prognostic factor in acute lymphoblastic leukemia. Blood 104: 2492-2498.

26. Xu CB, Shen JZ, Shen SF, Fu HY, Zhu YF, Chen L. (2010): The significance of methylation status of secreted frizzled-related 
protein gene promoter in acute leukemia. Zhonghua Nei $\mathrm{Ke} \mathrm{Za}$ Zhi., 49:769-771.

27. Hou HA, Chou WC, Lin LI, Chien-Yuanc C, Jih-Luh T, Mei-Hsuan T, Chi-Fei $H$, MingY, Shang-JU W, Shang-Yi H, Bo-Sheng K, Woei T (2011): Aberrant methylation of Wnt pathway inhibitors and its cooperation with other genetic alterations with distinct characteristics in acute myeloid leukemia. Haematologica 94:.220.

28. Griffiths EA, Gore SD, Hooker CM; McDevitt MA, Karp JE, Smith BD, Mohammad HP, Ye Y, Herman JG, Carraway HE. (2010): Acute myeloid leukemia is characterized by Wnt pathway inhibitor promoter hypermethylation. Leukemia \& Lymphoma 51:1711-1719.

29. Cytogenetics and Epigenetics of Acute Leukemia. July 2, 2011. Available at : http://www.Cancer Research/ Leukemia.

30. 30.Shen L, Kantarjian H, Guo Y, Lin E, Shan J, Huang Z, Berry D, Ahmed S, Zhu W, Pierce S, Kondo Y, Oki Y,
Jelinek J, Saba H, Estey E and Issa JP(2010). DNA methylation predicts survival and response to therapy in patients with myelodysplastic syndromes. J Clin. Oncol., 28:605-613.

31. Plimack ER, Kantarjian HM and Issa JP. (2007): Decitabine and its role in the treatment of hematopoietic malignancies. Leukemia \& Lymphoma 48:1472-1481.

32. Agrawal S, Unterberg $M$, Koschmieder S, zur Stadt U, Brunnberg $\mathbf{U}$, Verbeek $\mathbf{W}$, Büchner T, Berdel WE, Serve H, Müller-Tidow C (2007): DNA methylation of tumor suppressor genes in clinical remission predicts the relapse risk in acute myeloid leukemia. Cancer Research 67:1370-1377.

33. Veeck J, Niederacher D, An H, Klopocki E, Wiesmann F, Betz B; Galm O, Camara O, Dürst M, Kristiansen G, Huszka C, Knüchel $R$ and Dahl E (2006): Aberrant methylation of the Wnt antagonist SFRP1 in breast cancer is associated with unfavorable prognosis. Oncogene 25:3479-3488. 


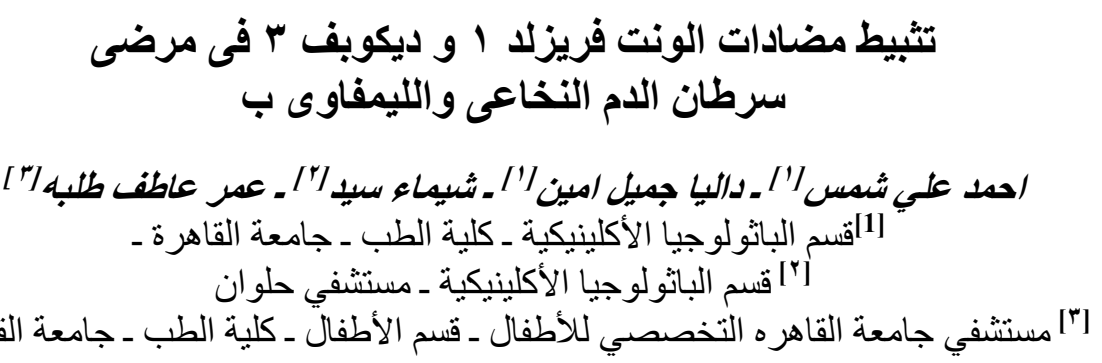

تلعب بروتينات الونت دوراً هاماً فى العمليات الحيوية للخلية حيث أن لها دور أرئيسياً في تثكيل الخلايا

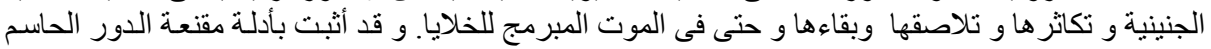

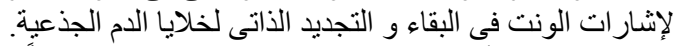

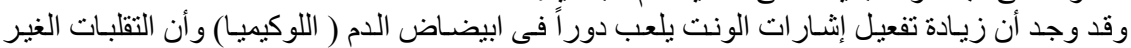

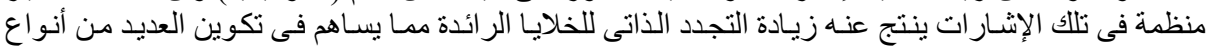
اللوكيميا.

و ينحكم في إثدار ات الونت العديد من المضسادات الطبيعية بالجسم و التى تتدخل مع مستقبلات التفاعل

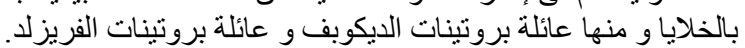

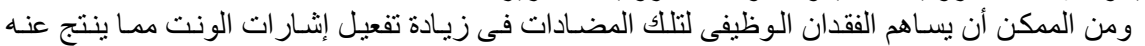

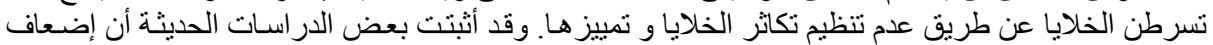

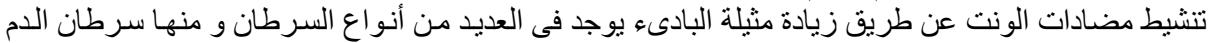
بأنو اعه: النخاعى و الليمفاوى و المايلوما المتعددة.

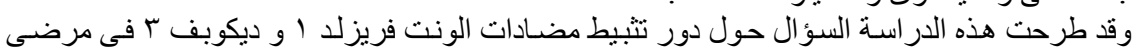

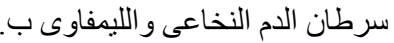

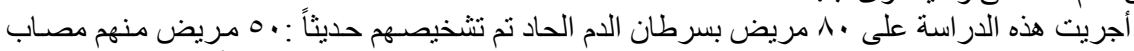

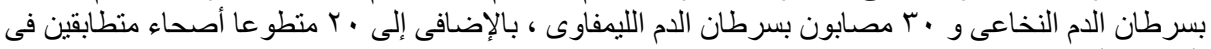

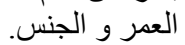

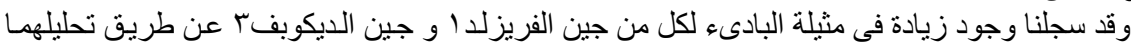

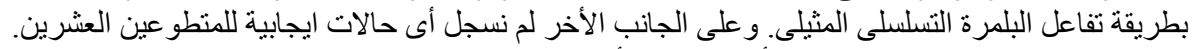

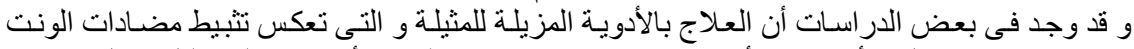

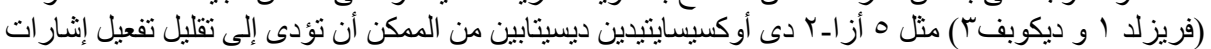
الونت فى حالات اللوكيميا الحادة.

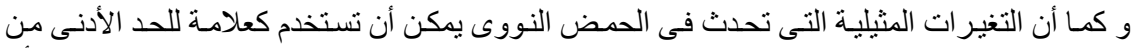

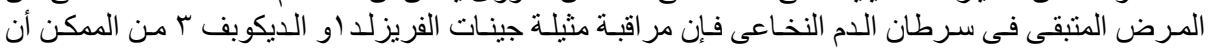

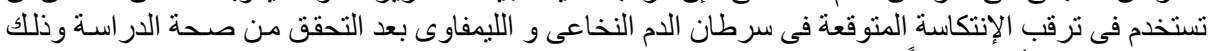

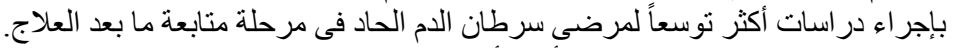

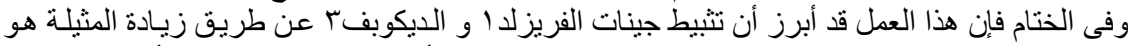

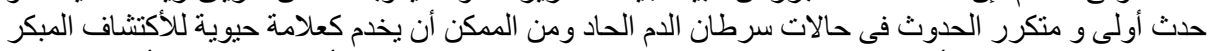

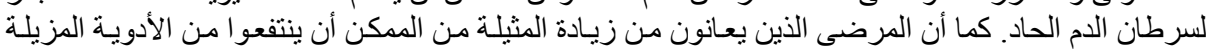

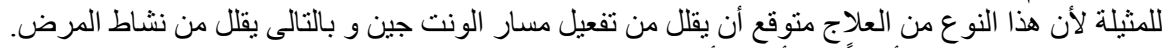

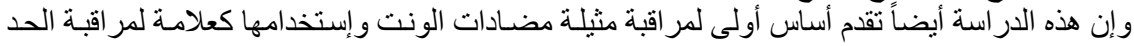

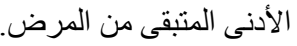

